\title{
La aventura imperial de España en la revolución haitiana. Impulso y dispersión de los negros auxiliares: el caso de San Fernando Aké, Yucatán
}

\author{
Jorge Victoria Ojeda \\ Jorge Canto Alcocer ${ }^{*}$
}

\begin{abstract}
Resumen
Los autores de este artículo relatan la adhesión de una parte de las tropas rebeldes negras a los intereses españoles que pretendían reconquistar totalmente la isla de Santo Domingo, la pérdida de aquella colonia y la dispersión de esas tropas por diversas partes del imperio español a fines del siglo xviı. Parte medular del trabajo es la llegada de algunas tropas del caudillo rebelde Jean François a tierras yucatecas, y la fundación de un poblado para su estancia, acorde a las promesas hechas por Carlos IV para conseguir su alianza.
\end{abstract}

\begin{abstract}
The autors of this paper research the adhesion by part of the black rebel troops to Spanish interest of total reconquest of the island of Santo Domingo, the loss of that colony, and the subsequent dispersion of the troops throughout the Spanish empire at the end of the eighteenth century. The research centers around the arrival in Yucatan of some of Jean François' rebel troops, and the creation of a township to accomodate them, as part of the promises made by king Carlos IV to guarantee their allegiance.
\end{abstract}

Palabras clave:

Afroamericanos, Haití, revolución haitiana, negros auxiliares, San Fernando Aké.
Fecha de recepción: enero de 2000

Fecha de aceptación: junio de 2000

*Jorge Victoria Ojeda: Investigador del Archivo General del Estado de Yucatán. Correo electrónico: victoria61@latinmail.com

Jorge Alberto Canto Alcocer: Jefe del Archivo Histórico del Archivo General del Estado de Yucatán. Correo electrónico: jacanto68@hotmail.com 


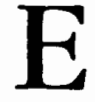

1 presente artículo trata sobre el poblado de San Fernando Aké, situado en Yucatán, en el periodo comprendido entre fines del siglo XVIII y mediados del XIX. El tema central gira en torno al episodio que dio origen a la fundación de dicho pueblo, estrechamente relacionado con la intervención española en la rebelión de los esclavos negros de Saint-Domingue, hoy Haití, en ese entonces colonia francesa.

\section{LA REVOLUCIÓN FRANCESA EN SAINT-DOMINGUE}

La isla de La Española, descubierta por Cristóbal Colón en el transcurso de su primer viaje, un par de meses después de su llegada a América, y colonizada desde ese momento por el imperio español, atravesó por el proceso de aniquilamiento de la población indígena común al área caribeña en sus prime. ras décadas de vida. ${ }^{1}$ Sólo un par de décadas después del primer contacto, ya el humanista fray Bartolomé de las Casas gestionaba ante la corona la introducción de esclavos africanos en esa isla como un intento por preservar a los escasos miles de indígenas -de una población precolombina estimada en, aproximadamente, 200000 habitantes ${ }^{2}$ que habían sobrevivido a la invasión europea. ${ }^{3}$ Los esclavos introducidos dieron rápidas muestras de rechazo a su estancia y su circunstancia en la isla caribeña, protagonizando

\footnotetext{
${ }^{1}$ Pichardo, Resumen, 1922, pp. 14-15.

${ }^{2}$ Grafenstein, Haiti, 1988, p. 12.

${ }^{3}$ Pichardo, Resumen, 1922, p. 31.
}

rebeliones y motines prácticamente desde su llegada. ${ }^{4}$

La estratégica posición de La Espa. ñola -con el paso del tiempo más conocida como Santo Domingo, nombre de su capital-, en el centro del mar Caribe, considerada como una de las "llaves" del dominio español en la zona, ${ }^{5}$ motivó la ambición de Francia, Inglaterra y Holanda, seculares enemigas del imperio español. Así, las invasiones piratas a la isla provenientes de dichos países se sucedieron desde los inicios del periodo colonial, ${ }^{6}$ y fructificaron finalmente los esfuerzos de los franceses con la conquista de la región occidental de la misma, la cual fue aceptada por España en 1697 con la firma del Tratado de Ryswick. ${ }^{7}$ No obstante, la corona española no abandonó la lucha por el dominio caribeño, y se mantuvo a la expectativa de recuperar los territorios que le eran arrebatados por sus rivales -como en el caso del, desde entonces, llamado Saint-Domingue francés- recurriendo incluso a las tácticas del corso para responder a las agresiones externas. $^{8}$

El Saint-Domingue francés, como todo el imperio de Luis XVI, fue conmocionado por la revolución de 1789.9

\footnotetext{
${ }^{4}$ La primera rebelión de esclavos negros en La Española estalló en 1522, Pichardo, ibid., p. 33 .

${ }^{5}$ Zapatero, Guerra, 1990, p. 5; Victoria, Mérida, 1995, p. 239.

${ }^{6}$ Pichardo, Resumen, 1922, pp. 38-41.

${ }^{7}$ Grafenstein, Haití, 1988, pp. 42-44.

${ }^{8}$ Zapatero, Guerra, 1990, p. 288.

${ }^{9}$ La revolución de la burguesía francesa contra el Antiguo Régimen, marcada en su inicio por la convocatoria de los Estados Generales a principios de 1789, la rebelión del Tercer Estado (burgués) contra las disposiciones reales, y
} 
La oligarquía dominante, conformada en su gran mayoría por colonos blan$\cos$, dueños de plantaciones de azúcar, algodón y añil, ${ }^{10}$ inició la agitación desde el anuncio de la convocatoria de los Estados Generales, en la que por cierto, no fueron incluidos, con la pretensión de presionar a la metrópoli a decretar la libertad comercial. ${ }^{11}$ Los propietarios negros y mulatos, dueños tanto de grandes producciones azucareras, como de pequeñas propiedades cafetaleras, ${ }^{12}$ propugnaban por el respeto al principio revolucionario de igualdad entre los hombres libres, es decir, el cese de la discriminación, ${ }^{13}$ aunque no consentían en abolir la esclavitud, por contravenir a sus intereses. ${ }^{14}$ En cuanto a los esclavos, hemos señalado ya su proclividad a la rebelión, misma que se manifestó más crudamente desde mediados del siglo $\mathrm{xVW}$, con un aumento considerable del

la toma de la Bastilla el 14 de julio del mismo año, estableció los principios de "libertad, igualdad y fraternidad". Entre sus consecuencias primordiales, de mayor influencia en SaintDomingue, destacan la declaración de libertad de todos los ciudadanos franceses ante la ley, y el establecimiento de la libertad comercial.

${ }^{10}$ Grafenstein, Haití, 1988, p. 25; Grafenstein, Nueva, 1997, pp. 44, 57, apunta que entre 1760 y 1791 Saint-Domingue era el productor de azúcar más grande del mundo.

${ }^{11}$ Joachim, "Racines", 1988, p. 164.

${ }^{12}$ Grafenstein, Haití, 1988, p. 25.

${ }^{13}$ Franco, Rebeldias, 1975 , p. 3 . Entre las leyes discriminatorias contra los negros, las cuales alcanzaban aun a los grandes y medianos propietarios, tenemos la prohibición del uso de espadas, de nombres franceses, de los títulos de "señor" y "señora", de trabajar en la burocracia y el ejército, y del ejercicio de algunas profesiones y oficios. Grafenstein, Haití, 1988, p. 49.

${ }^{14}$ Joachim, "Racines", 1988, pp. 166-167. cimarronaje, es decir, la deserción de los esclavos de las plantaciones, su huida a zonas poco accesibles y la formación de poblados clandestinos protegidos por grupos de rebeldes armados. ${ }^{15}$ La agitación revolucionaria también se hizo presente en este grupo, tanto entre los fugados como entre los dominados que trabajaban en las fincas. Así, en Bosque Caimán, la noche del 14 de agosto de 1791 -dos años después de la toma de la Bastilla por los revolucionarios metropolitanos- esclavos y cimarrones encabezados por un sacerdote vudú, llamado Boukman, juraron -según las memorias en medio de una pavorosa ceremonia- luchar hasta liberarse completamente de la esclavitud y vengarse de sus amos blancos. ${ }^{16}$

La lucha abierta estalló una semana después, y cobró de inmediato formidables proporciones. Entre los líderes negros comenzaron a destacar Jean François, George Biassou y Jeannet. Prácticamente todo el país fue incendiado por la rebelión esclava. En noviembre murió en combate Boukman, siendo sus restos exhibidos ignominiosamente para tratar de desalentar el movimiento. El comando de la subleva. ción pasó a los otros líderes mencionados. $^{17}$

La cerrazón de la oligarquía, que se negó a aceptar la igualdad social y politica de los negros libres, llevó a grandes cantidades de libertos a unirse a la

${ }^{15}$ Ibid., pp. 167-168.

${ }^{16}$ Grafenstein, Haiti, 1988 , p. 57 . Respecto del importante papel del vudú en la cultura afrocaribeña ver Franco, "Vudú", 1988, pp. 128136; Franco, Rebeldias, 1975, p. 6.

${ }^{17}$ Franco, Rebeldias, 1975, p. 7. 
sublevación de los esclavos, con lo que el movimiento creció en poderío militar e influencia social. ${ }^{18}$

El gobernador español de Santo Domingo, Joaquín García, contactó con varios líderes rebeldes negros, probablemente hacia fines de 1791, ofreciéndoles -a cambio de su apoyo bélicoarmas, pertrechos, propiedades y, sobre todo, la libertad incondicional, adquiriendo el carácter de vasallos del rey de España. ${ }^{19}$ Las promesas fueron formalizadas por real orden del 22 de febrero de $1793 .{ }^{20}$ Algunas autoridades hispánicas denunciaron ingenuamente las maniobras de García, sin saber que detrás de ellas estaba el interés imperial del propio monarca. Así, el gobernador de Luisiana, barón de Carondelet, acusó a García ante el conde de Aranda, en carta del 20 de octubre de 1792, "de haber fomentado el levantamiento de la gente de color en aquella isla". 21

${ }^{18}$ Joachim, "Racines", 1988, pp. 166-167.

19 "El regente de la Real Audiencia de Santo Domingo a V. E. Santo Domingo, enero 23 de 1796", Archivo General de Indias (en adelante, AGI), Santo Domingo, leg. 1033; "Sobre establecer en esta provincia de Yucatán a 115 negros que de las tropas auxiliares de Santo Domingo remitió a ella el excmo. señor gobernador de la Habana", Archivo General de la Nación (en adelante, AGN), Marina, exp. 5, vol. 99; Franco, Historia, 1971, pp. 218-219.

20 "El virrey Marqués de Branciforte comunica las noticias que le han participado los gobernadores de Guatemala y Yucatán sobre los negros auxiliares de la isla de Santo Domingo que le remitió el de La Habana", AGI, Estado, 24, N. 53. Aunque la real orden está fechada en 1792, hace referencia a la muerte de Luis XVI, que ocurrió el 21 de enero de 1793, por lo que indudablemente la datación está errada.

${ }^{21}$ Franco, Historia, 1971, p. 219.
Los principales jefes rebeldes, Jean François, Biassou y Toussaint-Louverture -antiguo secretario de Biassou que comenzaba a brillar por sí mismo- aceptaron la oferta hispana, conformándose las llamadas tropas auxiliares. Para atraerse a estos líderes, García utilizó los servicios del padre José Vázquez, hombre conocido por su habilidad como negociante. ${ }^{22} \mathrm{~A}$ los jefes militares les fueron concedidas altas graduaciones, y recibieron condecoraciones y homenajes de las autoridades españolas, ${ }^{23}$ mismas que además, sancionaron el gobierno que ejercían de facto los insurgentes, en los territorios conquistados.

Toda esta actividad subversiva española fue llevada a cabo a pesar de no haber sido declarado el estado de guerra con Francia, y constituye una obvia manifestación del deseo imperial de

\section{${ }^{22}$ Ibid., p. 241.}

${ }^{23} \mathrm{Al}$ respecto, la documentación apunta que Jean François fue condecorado con la faja $e$ insignia de los oficiales generales de los ejércitos y la armada del rey, que sus subordinados estaban revestidos de insignias militares, y que se conducía en gran coche de seis caballos, lujo que ni el propio gobernador de Cuba se daba, según su propio testimonio. "Carta del Gobernador de La Habana al Príncipe de la Paz, dando cuenta del envío de los auxiliares a $\mathrm{Cu}$ ba", AGI, Estado, 5B, N. 176. Por su parte, el gobernador García refirió al duque de Alcudia haber recibido las medallas de oro para François, Biassou y Jacinto, y doce de plata para jefes de menor rango. A la súbita muerte de Jacinto, la medalla en cuestión le fue entregada a Toussaint-Louverture. "Noticias de la parte francesa de Santo Domingo", AGI, Estado, 14, N. 89; "Informando haberse restituido a Bayajá Juan Francisco", AGI, Estado, 14, N. 77; "Gobernador de Santo Domingo acusa recibo de correspon. dencia", Estado, 14, N. 86. 
reconquistar la totalidad de la isla. ${ }^{24} \mathrm{Fi}$ nalmente, la guerra entre ambos Estados se declaró de manera oficial -tras la decapitación de Luis XVI-, el primero de febrero de 1793.

Desaveniencias entre Toussaint y Jean François llevaron al primero, que se había convertido en el caudillo principal de los auxiliares, a entrar en tratos con los franceses en marzo de 1794, quien se pasó definitivamente a ese bando el 18 de mayo, a la cabeza de más de 5000 hombres, después de que los franceses se comprometieran a abolir la esclavitud. ${ }^{25}$ Toussaint fue nombrado comandante general de la línea francesa del oeste, llegando posteriormente a gobernar toda la isla. ${ }^{26}$ Con el apoyo de los ejércitos negros, los fran. ceses expulsaron de su territorio a las milicias hispanas, en las cuales continuaron sirviendo los hombres al mando de Jean François y Biassou. ${ }^{27}$

La derrota española en la guerra quedó finalmente sellada por la firma, en julio de 1795, del Tratado de Paz de Basilea, por el que la totalidad de Santo Domingo quedó en poder de Francia. ${ }^{28} \mathrm{El}$ gobernador español, García,

${ }^{24}$ Bautista, Estrategia, 1992, pp. 244-245.

${ }^{25}$ Franco, Rebeldias, 1975, pp. 8-10; Franco, Historia, 1971, pp. 229, 239.

${ }^{26}$ Franco, Rebeldias, 1975 , p. 10

${ }^{27}$ Valdez, Historia, 1964, pp. 202-204; Franco, Historia, 1971, p. 240.

${ }^{28}$ En sus memorias, el artífice del tratado, Manuel Godoy, la eminencia gris de la corona española en aquellos años, señala en un intento de justificar la irrecusable derrota ibérica: "Ningún tratado de la Francia con las demás potencias en aquella época ofreció menos sacrificios $[\ldots]$ si es que puede llamarse sacrificio la cesión de la parte española de la isla de Santo Domingo, tierra ya de maldición para los blancos y dispuso entonces el traslado a Cuba de las tropas auxiliares para evitar la masacre que, seguramente, hubieran sufrido de caer en manos francesas. ${ }^{29}$ Para mayor seguridad en la travesía, García mandó que el padre Vázqueź que, como ya hemos dicho, ejercía influencia sobre los caudillos, los acompañase. ${ }^{30}$

\section{EVACUACIÓN DE LAS TROPAS AUXILIARES}

El 9 de diciembre de 1795, el gobernador García comunicó al de Cuba, Luis de las Casas: "Su resolución de enviar a este puerto al general Juan Francisco [Jean François] y a todos los caudillos de los negros auxiliares que, desde el principio de la guerra, abrazaron el partido del rey". 31

La noticia no fue bien recibida por las autoridades cubanas. El gobernador Las Casas escribió alarmado a Manuel Godoy, presidente del Consejo de Ministros de la corona, apenas recibió la comunicación de García:

Esta noticia ha llenado de terror a los habitantes blancos de la ciudad y de la

verdadero cáncer agarrado entre las entrañas de cualquiera que fuera su dueño en adelante. Nuestros principales colonos la tenían ya de hecho abandonada; su posesión era una carga y un peligro continuo; muchas poblaciones y parroquias habían sucumbido por la dura necesidad al poder anárquico de los negros y mulatos". Citado en Guerrero, Santo, 1986, p. 35.

${ }^{29}$ Valdez, Historia, 1964 , pp. 202-204; Landolfi, "interpretación", 1977, pp. 170-171; Franco, Historia, 1971, p. 240.

30 "Expediente sobre la revolución y guerra de la colonia francesa. Años de 1796 a 1798", AGl, Santo Domingo, leg. 1033.

31 "Carta del gobernador de La Habana al Príncipe de la Paz", AGI, Estado, 5B, N. 176 

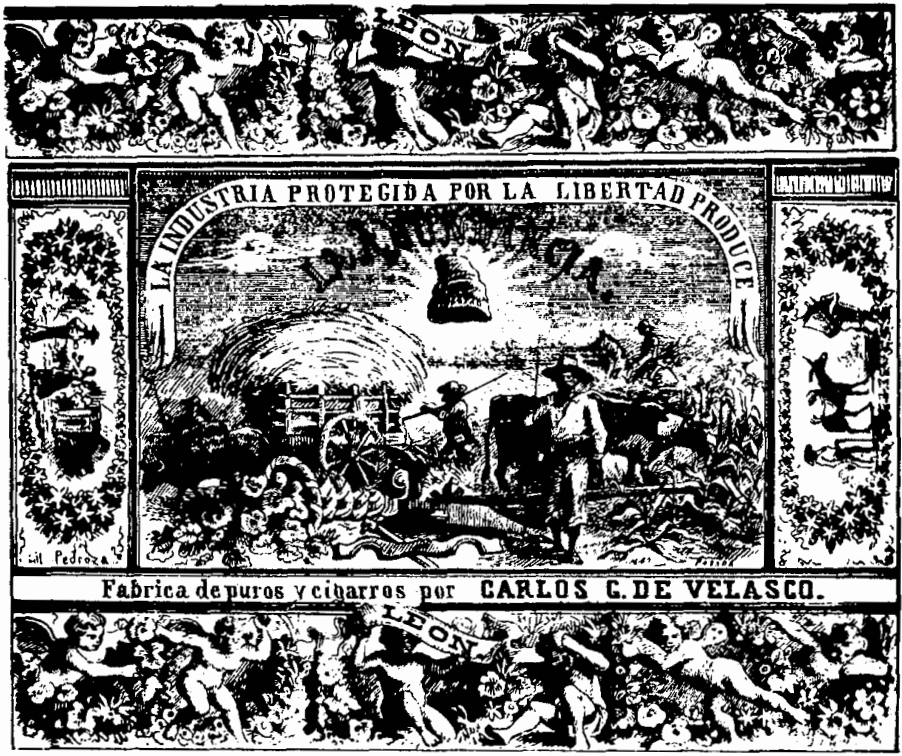

isla, cada vecino cree ver el momento de la insurrección de sus esclavos, y el de la desolación universal de esta colonia en el momento de la aparición de estos personajes, esclavos miserables ayer, héroes hoy de una revolución, triunfantes, opulentos y condecorados; tales objetos no son para [ser] presentados a la vista de un pueblo compuesto en la mayor parte de hombres de color que viven en la opresión de un número más corto de blancos $[\ldots]$

Ante el sombrío panorama esbozado por él mismo, Las Casas aseveró tajante al final de su comunicación: "[...] jamás consentiré la entrada de estas gentes sin expresa orden de S. M.". ${ }^{32}$

\footnotetext{
${ }^{32}$ lbid.
}

Entonces pretendió impedir el traslado a Cuba de los negros auxiliares; pero ante la imposibilidad de enviar el aviso a tiempo, convino con el comandante general de Marina preparar embarcaciones para diseminar a los caudillos negros, mandando algunos a Cádiz o a las islas Canarias, y otros a Florida y a la isla de Pinos. ${ }^{33}$

Las tropas auxiliares partieron de Santo Domingo en varios buques a mediados de diciembre de 1795. Una parte de ellas lo hizo en la escuadra española que, al mando del teniente general de la Real Armada, Gabriel de Aristizábal y Espinoza, trasladó a La Ha-

${ }^{33}$ Ibid. 
bana los supuestos restos de Cristóbal Colón. ${ }^{34}$ Biassou y su familia viajaron en el navío de guerra San Lorenzo, que partió del puerto de Ocoa unos días antes que los hombres de Jean François. Las Casas le propuso su inmediato traslado, junto con sus 23 familiares, a la Florida, lo que el caudillo negro aceptó. ${ }^{35}$

El problema principal lo constituía el grupo comandado por Jean François, compuesto por 707 individuos, incluyendo mujeres y niños. A este comandante, Las Casas le propuso pasar a España en compañía de su familia, en tanto que el resto de los negros serían trasladados a la isla de Trinidad en calidad de colonos. Inicialmente, Jean François rechazó la idea del viaje a la metrópoli, optando por acompañar a los demás auxiliares hacia Trinidad. ${ }^{36}$ Sin embargo, finalmente fue convencido de viajar a Cádiz, lo que hizo en compañía de doce jefes militares, algunos oficiales, y sus familias y servidumbre, un total de 136 personas, ${ }^{37}$ llegando a

${ }^{34}$ Franco, Historia, 1971, p. 240.

35 "El capitán general da cuenta de los jefes y negros auxiliares que han llegado a la plaza de La Habana", 11 de enero de 1796, Archivo General de Simancas (en adelante, AGS), Scretaría de Guerra, 7161, exp. 24. Sobre el envio y estancia de este grupo de negros en la Florida, consúltese Landers, "Rebellion", 1997, pp. 156-177.

36 "El capitán general da cuenta de los jefes y negros auxiliares que han llegado a la plaza de La Habana", 11 de enero de 1796, AGS, Secretaría de Guerra, 7161, exp. 24.

37 "Sobre la estancia en España del caudillo Juan Francisco", 1796, AG1, Estado, 3, N. 10; Grafenstein, Nueva, 1997, p. 266, asegura que Jean François fue remitido a la costa de Mosquitos y no a España. La misma autora (p. 267, nota 84), señala que: "En contradicción con datos hallados en la correspondencia oficial de
Cádiz en el mes de marzo de 1796. En el siguiente octubre se resolvió enviar al grupo a la costa de Mosquitos, en la capitanía general de Guatemala. ${ }^{38}$

Ya sin la presencia de Jean François y Biassou, Las Casas dispuso el traslado de los negros restantes a diferentes puntos americanos en tierra firme: al puerto de Campeche fueron enviados 115 auxiliares, 310 al de Trujillo ${ }^{39}$ y 90 al de Portobelo. ${ }^{40}$ Según José Luciano Franco, cierto número de ellos fue mandado a la isla de Trinidad (véase figura 1). ${ }^{41}$ Efectivamente, como hemos mencionado, se pasó en dicha isla ini-

Nueva España, prevalecía entre muchos con. temporáneos la idea de que Jean François se embarcó con todos sus oficiales a disfrutar en Europa los honores y dignidades con los que han sido investidos por sus patrones de la corte de Madrid". Con base en los datos aportados por el documento referente a la presencia de ese caudillo en la península ibérica, damos por segura su estancia temporal en Europa. La aseveración de Grafenstein al respecto, puede deberse a que el documento que cita (AGN, Co. rrespondencia de virreyes, vol. 187) proviene del 27 de marzo de 1797, año en que François y su gente eran remitidos de España a Centroamérica, sin que se haga mención de su procedencia de Cádiz. Por otra parte, un dato curioso es que, en 1796, se señala el envío a España de 136 personas, $y$ al año siguiente el número ya había ascendido a 142.

38 "El capitán general da cuenta de los jefes y negros...", AGS, Secretaria de Guerra, 7161, exp. 24; "Auxilios negros de Santo Domingo. Destinos", AGS, Secretaría de Guerra, 6973, exp. 43.

39 "El virrey marqués de Branciforte comunica...", AGI, Estado, 24, N. 53; "Branciforte a Varela", 27 de julio de 1797, AGN, Correspondencia de virreyes, vol. 186, N. 1041 , f. 201.

40 "El virrey de Santa $\mathrm{Fe}$ al conde de Santa Clara", Santa Fe a 19 de agosto de 1797, AGI, papeles de Cuba, 1517B.

${ }^{41}$ Franco, Historia, 1971, p. 241. 
cialmente como destino de los negros; sin embargo, disposiciones posteriores indicaban una absoluta negativa de las autoridades reales a ello, tal como lo señaló Godoy, también conocido como el Príncipe de la Paz, en comunicación a Miguel José de Azanza, ministro de Guerra:

deseando S. M. emplearles [a los negros auxiliares] en algún paraje de sus dominios de América, espero que me diga V. E. si podrá destinarse a dichos jefes negros con sus familias en Puerto Rico $u$ otra de las posesiones del rey que no sea la isla de Cuba ni la de Trinidad de barlovento. ${ }^{42}$

\section{LOS NEGROS AUXILIARES EN YUCATÁN}

El 10 de febrero de 1796 llegaron al puerto de Campeche, a bordo de la fragata mercante "la amable María Rosa" a cargo de don Manuel Núñez, los 115 negros que el gobernador Las Casas dispuso se dirigiesen a ese destino,

42 "El capitán general da cuenta de los jefes y negros", AGS, Secretaría de Guerra, 7161, exp. 24 (las cursivas son nuestras) Ver también: "Sobre estancia en España ...", AGs, Estado, 3, N. 10 , donde se señala lo arriesgado e inconveniente de enviar a los negros a las islas, en virtud de su posible convivencia con los de color alli asentados. Un inconveniente para el envio de los negros a Trinidad lo constituyó, sin duda, lo apuntado por el conde de Floridablanca en 1797, en relación al gran valor estratégico atribuido a aquella isla que, por su ubicación geográfica, era la más indicada para la defensa de las posesiones españolas en la zona: "y por esto he querido que no sólo se pueble y fortifique aquella isla, sino que se habilite en ella un buen puerto a costa de cualquier cuidado", Grafenstein, Nueva, 1997, p. 125. jefaturados por los siguientes oficiales: el comandante Marcos, los coroneles Juan Pedro y Ambrosio Sasy, y el capitán Juan Casimiro. Además, venían 59 hombres de tropa, 35 mujeres, seis muchachos "con ración" y once niños "de pecho". ${ }^{43}$

En sus instrucciones respecto de los negros auxiliares, Las Casas señaló a Arturo O'Neill, gobernador de Yucatán, la existencia de tres reales órdenes -de 22 de febrero de 1793, 24 de diciembre de 1794 y 26 del mismo mes y año, respectivamente- por las cuales la corona concedía amparo y protección a los auxiliares. Por ello, el gobernador de Cuba le informó a su homólogo que la subsistencia de estos hombres corría a cargo de la Real Hacienda. ${ }^{44}$

Diez días después de la llegada de las tropas auxiliares, O'Neill convocó a Junta de Real Hacienda para tratar el asunto de la manutención y establecimiento de los negros. Allí se acordó asignarles un real diario del aprobado real y medio que les habían destinado los ministros de la Real Hacienda de Campeche durante los días previos, así como convocar a las autoridades de los negros para acordar con ellas los medios más adecuados y económicos para su asentamiento provisional. ${ }^{45}$

El 26 de febrero, los oficiales negros se presentaron ante la Junta provincial en Mérida manifestando su deseo de que se les señalase un sitio fértil para vivir, donde pudieran practicar la agricultura, solicitando también se les pro-

\footnotetext{
43 "El virrey marqués de Branciforte comunica ...", AGI, Estado, 24, N. 53.

${ }^{44}$ Ibid.

${ }^{45}$ Ibid.
} 
porcionasen útiles de labranza, semillas y víveres para su subsistencia inicial. Asimismo pretendían continuar cobrando el sueldo que se les tenía asignado durante la campaña en Santo Domingo. ${ }^{46}$

La resolución de la junta, que únicamente rechazó esta última petición, se formalizó en un reglamento otorgado el primero de marzo del citado año, ordenando los procedimientos a seguir para el asiento -que aún se contemplaba como interino- de los negros en la provincia. ${ }^{47}$

En el reglamento se comisionaba a don Luis Ojeda -con un sueldo de 25 pesos mensuales- para deslindar el terreno en que se establecieran los negros, habiéndose señalado por el gobernador que debería hallarse entre los pueblos de Sucopó, Dzonot Aké, Río Lagartos y El Cuyo, "el que le parezca mejor [...] que no esté en bajo y sí en donde haya buen agua, y no inmediato a pantanos [...]". Su ubicación debía acordarla con el subdelegado de Tizimín, a quien también se encargó de recibir a los negros y de cuidar el orden durante su traslado y establecimiento (véase la figura 2).

Una vez ubicado el terreno, se levantarían tres galerones de guano de 60 varas $^{48}$ cada uno, para alojarlos mandándose que su distribución formase una plaza que mirara al oriente, po-

\footnotetext{
${ }^{46} \mathrm{Ibid}$.

${ }^{47}$ Este reglamento provisional se encuentra en ibid.

${ }^{48}$ La vara castellana era una medida de longitud equivalente a 83.5 centímetros. Los aspectos referentes a la conformación del poblado de acuerdo con los lineamientos borbónicos han sido abordados en Canto y Victoria, "San", 2000, pp. 163-167.
}

niente y sur, respectivamente. Además, se dispuso la construcción de una habitación para el "intérprete" -funcionario que tendría además a su cargo la administración de los víveres, y que gozaría de un sueldo de doce pesos mensuales-, una casa para troje y otra para cárcel, con cepo y dos grilletes.

Previendo que el asentamiento perdurase, el reglamento estipuló que, si los negros deseaban construir sus propias casas, habría de ser en calles rectas que mirasen de oriente a poniente y de norte a sur, de doce varas de ancho, y formando cuadras de cien varas castellanas cada una. En ese mismo sentido, aunque el reglamento no contemplaba ninguna disposición relativa a la repartición de solares, sí se hacía la reflexión de que, en caso de que su majestad dispusiese la permanencia del pueblo, se procediese a dicha distribución.

En materia religiosa, se dispuso avisar al obispado del nuevo poblado para que la diócesis enviase a un sacerdote de alguna parroquia cercana, que administrase los sacramentos, indicándose que, hasta el establecimiento definitivo, no deberían cobrarse obvenciones.

Como medida de salud pública, se mandó que las milpas se sembrasen circundando la localidad, de tal manera que ésta quedara completamente desmontada.

El citado ordenamiento estipulaba la entrega al intérprete, y éste a los negros, de 100 hachas, 100 machetes, 25 picos, 25 azadas, cuatro barretas grandes y cuatro picos de cantero, cuyo valor se les descontaría a los auxiliares de su asignación. Para la fabricación de estos artefactos, se dispuso la utilización 
de los cañones viejos e inútiles existentes en ese entonces en la ciudadela de San Benito.

Para el establecimiento inicial del poblado, se ordenó al subdelegado de Tizimín comprase, en las inmediaciones del lugar, 2000 cargas de maíz, cuyo consumo sería regulado por el intérprete, con la asignación de cuartillo y medio por persona. Asimismo, se indicó el abastecimiento de carne, a razón de una res cada dos días, tocándole a cada individuo libra y media de carne con hueso diariamente. ${ }^{49}$ También dispuso que, de la cuenta de la Real Hacienda, se les proveyese de dos molinos de fierro para "moler el maíz según acostumbran", dos ollas de barro y un almud de sal por familia, y un plato de barro por persona.

Además de las funciones antes mencionadas, el intérprete quedó a cargo de la seguridad, con instrucción específica de:

celar muy escrupulosamente sobre la conducta y las conversaciones públicas o secretas de los indicados negros, y al menor rumor de descontento o de propagación de las perniciosas máximas de la igualdad, libertad o falta de subordinación [...] dará cuenta inmediatamente con toda reserva al subdelegado del partido $[\ldots]$.

De acuerdo con el reglamento, el "gobierno económico" de los negros quedó a cargo de su comandante Marcos, lo que probablemente haga referencia a la responsabilidad sobre su organización laboral, aprovechando

\footnotetext{
${ }^{49}$ La libra era una antigua medida de peso cuyo valor equivale alrededor de 400 gramos.
}

su autoridad como oficial de mayor rango para desempeñar esta función.

El reglamento prohibió el traslado de los negros a "pueblos de indios" y a la costa, sujetándolo a expresa licencia de la propia capitanía general, y estipulándose que en ningún caso se permitiría que los negros fijaran su residencia en otro sitio. Si bien no hacía ninguna referencia expresa al paso o asentamiento de indios y españoles en el poblado, las propias circunstancias de relativo aislamiento de éste permiten inferir la intención de inhibir el contacto de los auxiliares con la población circundante.

Los sueldos de los funcionarios, los víveres, las semillas, las legumbres y los utensilios, se les descontarían a los negros de su asignación, entregándoles únicamente medio real al día, es decir, la mitad de lo estipulado inicialmente, con lo que pudieren "comprar gallinas y otras cosas que por menudas no se les provee de ellas".

Se autorizaba tácitamente la entrada de vendedores, pero se prohibía expresamente el comercio de alcohol, "por ahora". 50

Aun cuando nada en el reglamento parece referirse a ello, el gobernador de Yucatán expresó al virrey de Nueva España su esperanza de que los negros introdujeran a la provincia "el verdadero método de cultivar la caña dulce, beneficiar la azúcar, el añil, café y otras producciones [...]".51

Esta intención del gobernante yucateco respondía a un momento históri-

\footnotetext{
50 "El virrey marqués de Branciforte comunica...", AGI, Estado, 24, N. 53.

${ }^{51}$ Ibid.
} 
co, el de la consolidación de las reformas borbónicas en Yucatán, con el establecimiento de la intendencia en 1788 . En el caso de San Fernando Aké, tal establecimiento se vincula con los aspectos económicos de dicha reforma, ya que los individuos negros del Caribe eran tenidos en la provincia yucateca como excelentes trabajadores agrícolas, cuyos conocimientos y actividad harían florecer la agricultura comercial en tierras que, en esos tiempos eran escasamente explotadas. Respecto a ello, contamos con la representación del vecino de Campeche, Juan Ignacio de Cosgaya, quien en 1787 solicitaba a Carlos III autorización para importar un millar de negros caribeños

para el fomento y beneficio de sus tierras, porque de lo contrario, careciendo de los sirvientes en los trabajos será imposible conseguir los adelantamientos de la agricultura y comercio que se apetecen y tanto interesan a su majestad $[\ldots] .{ }^{52}$

En comunicación de 22 de abril de 1796, O'Neill indicó al virrey, marqués de Branciforte, las medidas de seguridad dictadas, que agregaban a las ya mencionadas, la existencia en las inmediaciones de 1000 soldados dispuestos a actuar "al menor aviso de cualquiera novedad en los negros".

O'Neill consultó tambiên a Branciforte sobre la conveniencia de suspender, al logro de la primera cosecha, el subsidio de un real diario a los negros.

\footnotetext{
52 "Real orden del ministro Valdés al virrey, despachada en San Ildefonso el 20 de septiembre de 1787", AGN, Reales Cédulas, vol. 138, exp. 135 , fs. 51-52.
}

Tras recibir las noticias sobre el establecimiento de los auxiliares, el virrey marqués de Branciforte comunicó al Príncipe de la Paz su desacuerdo con la presencia de dichos individuos en la provincia de Yucatán, pues,

[...] creo que no podrá convenir el establecimiento de unas gentes de su color que aumentaran el número de las castas infectas y que no les darán el mejor ejemplo con su carácter altivo y costumbres perniciosas.

Asimismo, el virrey añadió que el gobernador de Yucatán no había solitado caudales para la subsistencia de los negros, a diferencia del de Guatemala, que había demandado un socorro de 100000 pesos para el grupo de auxiliares llegado al puerto de Trujillo. ${ }^{53}$

\section{AKÉ: ASIENTO DE LOS NEGROS AUXILIARES}

El comisionado Ojeda escogió como asiento para el poblado de los negros auxiliares -según lo dispuesto en el acuerdo con el subdelegado de Tizimín- el sitio conocido como "Paraje Aké", ${ }^{54}$ que reunía las condiciones de

\footnotetext{
${ }^{53}$ Ibid. Los gastos de envío de Jean François y su gente a la costa de los Mosquitos le serían reintegrados por orden real al Reino de Guatemala por las cajas reales de Nueva España, previa comprobación de la suma erogada. "Branciforte a Juan Antonio Álvarez, marzo 27 de 1797", AGN, Correspondencia de virreyes, vol. 187, N. 798 , f. 84 .

54 "De la Comandancia Militar de Tizimín, sobre el destacamento de Río Lagartos y el establecimiento de negros San Fernando", 13 de abril de 1798, Archivo General del Estado de Yu-
} 
fertilidad en las tierras solicitadas por los negros, y de relativo aislamiento de los indios y vecinos estipulado por el gobernador " $[. .$.$] sin que estuviesen tan$ retirados de poblado que faltase quien celase sus costumbres y máximas". ${ }^{55} \mathrm{El}$ lugar elegido fue un antiguo sitio prehispánico de dimensiones considerables, que fue probablemente escenario de una de las más famosas batallas de la conquista de Yucatán. ${ }^{56}$

La localidad fue bautizada con el nombre de San Fernando, seguramente en honor del patrono de la monarquía española. ${ }^{57}$ Según O'Neill, el pueblo se localizaba "[...] a seis leguas al norte del pueblo de Dzonot Aké, tres de Río Lagartos, siete de la vigía de dicho río, y cinco de la del Cuyo [...]". ${ }^{58}$

catán (en adelante, AGEY), fondo Colonial, ramo Militar, vol. 1, exp. 13; "Instructivo del capitán general a José Carreño para desempeñar una comisión en el establecimiento de negros San Fernando Aké", 19 de julio de 1806, AGEY, fondo Colonial, ramo Militar, vol. 1, exp. 22; "Cuaderno de la provincia de Yucatán sobre comunicaciones del gobernador y capitán general don Benito Pérez Valdelomar", 20 de febrero de 1808 , Centro de Apoyo a la lnvestigación Histórica de Yucatán (en adelante, CAOHY), sección Manuscritos, caja VI, exp. 12.

55 "El virrey marqués de Branciforte comunica...", AGI, Estado, 24, N. 53.

${ }^{56}$ Este último tema se desarrolla ampliamente en la investigación "San Fernando Aké. Microhistoria de una comunidad afroamericana en Yucatán, (1796-1848)", realizada por los autores del presente artículo (inédita).

${ }^{57}$ Fernando III, rey de Castilla y de León en el siglo XII, fue canonizado en 1671 , y es considerado el protector de la monarquía española. Su festividad se celebra el 27 de mayo. O'Neill, Misal, p. 50.

58 "El virrey marqués de Branciforte comunica...", AGI, Estado, 24, N. 53.
Los negros fueron transportados de Campeche a Río Lagartos, pasando de allí al citado paraje durante la primavera de 1796. De acuerdo con las disposiciones reglamentarias, en su establecimiento debió estar presente el subdelegado de Tizimín y el intérprete, probablemente el sargento Eugenio Cano, quien para abril de 1798 ya había dejado su cargo, además de cuentas poco claras. ${ }^{59}$

En este último mes y año, ya se ha. bía decidido la permanencia definitiva del poblado, pues se estaba edificando la iglesia de acuerdo con el proyecto del ingeniero Rafael Lovet. ${ }^{60} \mathrm{Al}$ dejar el cargo, en abril de 1798, el sargento Cano informó a la Real Hacienda de los siguientes avances en su construcción:

Un mecate y medio de cal en zurcido que al poco más o menos tendrá de 5 a 6000 cargas.

Item dos cerros de piedras como de dos estados de alto, cada uno.

Item dos estados de sahcab poco más o menos de alto.

La mayor parte de los cimientos están abiertos. ${ }^{61}$

No obstante la anterior información, Isidro López, sucesor de Cano informó lo siguiente al hacerse cargo de los trabajos:

59 "De la Comandancia Militar de Tizimin...", AGEY, fondo Colonial, ramo Militar, vol. 1, exp. 13.

60 "Informe del comisionado José Carreño sobre la formación de habitantes del establecimiento de negros San Fernando Aké", 14 de octubre de 1809, AGEY, fondo Colonial, ramo Gobernación, vol. 1, exp. 7.

61 "De la Comandancia Militar de Tizimín...", 13 de abril de 1798, AGEY, fondo Colonial, ramo Militar, vol. 1, exp. 13. 
No habiendo en este nuevo establecimiento de negros los materiales que el sargento Eugenio Cano informó a V. S., pues sólo encontré un montón de madera cortada, con una poca piedra, sin embargo a que ya estaba seca dicha madera, resolví concluir el horno de cal que en efecto mandé encender, y por seca la citada madera [...] hecho 250 cargas de cal, encontré cuando más 50 cargas de sahcab y dos montoncitos de piedras. Tengo noticia dejó pagadas el insinuado sargento 400 cargas de sahcab al capitán Casimiro de negros, que no ha entregado todavía [...]

Asimismo, encontré solamente abierto el cimiento del bautisterio de la iglesia $[\ldots]$ sin otro principio alguno; en el día no sólo quedan enteramente abiertos sino al circular el pie de la obra, pues con la poca cal que produjo la madera seca y un nuevo horno que hice formar a la dirección de tres indios, que instruyeron a los negros, tengo ya la suficiente para continuar el trabajo sin suspensión. $^{62}$

En vista de las anteriores informaciones, es obvio que Cano aprovechó la lejanía del poblado para burlar las precisas disposiciones del reglamento sobre la contabilidad que debería llevarse de todos los gastos bajo su responsabilidad. Y es que, al parecer, los funcionarios españoles no perdían oportunidad de beneficiarse cuando la ocasión se presentaba, y su relación con los auxiliadores no fue la excepción. Hay el antecedente de que, durante la guerra en Santo Domingo, el administrador de las cajas reales de Bayajá, Juan Sánchez, se apoderó de los caudales y víveres a su resguardo, acu-

${ }^{62}$ Ibid. sando de los desmanes a Juan Francisco y su gente. ${ }^{63}$

Pese a que en su comunicación López indicaba que los trabajos de la iglesia se continuarían sin interrupción, lo cierto es que once años después, el comisionado del gobierno en el poblado, José Carreño, señalaba que debido a la suspensión de la obra, había mandado tejer una iglesia provisional de paja. $^{64}$

Pese a su establecimiento definitivo en San Fernando, los auxiliares no fueron incorporados en aquel momento a la vida institucional de la provincia. Por ejemplo, no obstante que en esas épocas, y por la necesidad de disponer a bajo costo de un mayor número de hombres para la defensa militar, se organizaron en las colonias americanas milicias con gente ajena al ejército activo, que incluyeron a "pardos y morenos", 65 pero estos no fueron alistados

63 "Expediente subcitado en Santo Domingo sobre la falta de caudales y demás intereses del rey perdidos en la plaza de Bayajá", 11 de abril de 1796, AGI, Santo Domingo, leg. 1038; "Declaración original dada y firmada por el negro Juan Francisco, jefe que fue de los de su color en la irrupción de la plaza de Bayajá", 16 de enero de 1801, AGI, Santo Domingo, leg. 1038.

64 "Informe del comisionado...", 14 de octubre de 1809, AGEY, fondo Colonial, ramo Gobernación, vol. 1, exp. 7; Bojórquez, "Haitianos", 1995, señala que Carreño fue enviado a San Fernando para someter a los negros ante el peligro de su insubordinación. Las verdaderas razones del envío de José Carreño a San Fernando han sido abordadas por Canto, "Revolución", 1999.

${ }^{65}$ Albi, Defensa, 1987, pp. 93-94. Cabe mencionar que en el proyecto original, las milicias se constituirian de unidades mixtas, con blancos, negros y mulatos integrados en el mismo cuerpo, pero ante la oposición de los blancos a 
para el servicio de las armas. Ello pudo deberse a la generalizada repulsión de las autoridades provinciales hacia los auxiliares por sus antecedentes revolucionarios. ${ }^{66}$ Para el caso, podemos mencionar la opinión de José Carreño, que los calificaba de "antropófagos" e "inferiores" ${ }^{67}$ la del gobernador Pérez Valdelomar, que en 1806 , dijo que miraba "[...] con desconfianza esta extraordinaria población [...]"68 y la ya citada del marqués de Branciforte, virrey de Nueva España. De igual manera, cabe recordar que el propio O'Neill dispuso su establecimiento en una zona geográfica distante de otras poblaciones y aun de la costa, recalcando aquel aislamiento con la prohibición de que los negros pasaran a las costas y los pueblos circundantes al suyo, para mantenerlos alejados de cualquier contacto con los habitantes de la región.

Por otro lado, las esperanzas de beneficio económico para la provincia resultaron defraudadas, pues los negros de San Fernando se dedicaron básica-

servir junto a hombres de color, se establecieron milicias separadas por criterios raciales, Albi, Defensa, 1987, p. 122.

${ }^{66}$ A diferencia de los aquí tratados, los auxiliares destinados a Florida y Centroamérica sí fueron incorporados a la milicia. Gazeta de Guatemala, t. 1, 8 de mayo de 1797; AGI, Guatemala, 805; AGI, Cuba, 357, "Compañía de pardos y morenos libres milicianos de Florida".

${ }_{67}$ 1807-1809, Negros, "Correspondencia de José Carreño, con informes al gobernador sobre sus actividades y contratiempos en el establecimiento de negros San Fernando Aké", AGEY, fondo Colonial, ramo Gobernación, vol. 1, exp. 6.

${ }^{68} 1806$, Negros, "Instructivo del capitán general a José Carreño para desempeñar una comisión en el establecimiento de negros San Fernando Aké", AGEY, fondo Colonial, ramo Militar, vol. 1, exp. 22. mente a la agricultura de subsistencia, sin ocuparse de manera significativa en los tipos de cultivo que supuestamente importarían como parte de su tradición cultural. ${ }^{69}$ En este sentido, es de notar que los auxiliares en lo particular no aplicaban la dinámica económica que prevenían las reformas borbónicas, y que suponía el aprovechamiento de su experiencia en el cultivo de la caña de azúcar. Un tanto por la distancia gubernamental ante estos negros, y otro por su propia decisión, su poblado mantuvo durante el dominio colonial una autonomía permitida, es decir, la que se da cuando el poder deja que los grupos étnicos se ocupen de sus propios asuntos y mantengan sus costumbres ${ }^{70}$ y, obviamente, no hubo motivación comercial para que ellos revivieran las labores realizadas en las plantaciones azucareras de Saint-Domingue.

\section{CONSIDERACIONES}

En el proceso de ajustes territoriales que la monarquía española había sufrido en el transcurso del siglo xviI, el episodio de los negros auxiliares de Santo Domingo se inscribe dentro de los intentos de la corona por recon-

69 "Padrón general de habitantes del pueblo de Kikil...", 12 de mayo de 1841, AGEY, fondo Poder ejecutivo, caja 40, ramo Censos y padrones, vol. 3, exp. 27; "De la primera autoridad de Sisantún al jefe político del partido", 13 de febrero de 1843, AGEY, fondo Poder ejecutivo, caja 52, sección Gobernación.

${ }^{70}$ Según este autor, este tipo de autonomía generalmente es resultado de la imposibilidad del Estado de imponer su voluntad. Díaz, Autonomia, 1996, pp. 150-151. 
quistar espacios geográficos perdidos. De ahí que aprovechara la inestabilidad de su vecina Francia, y particularmente sus efectos en Saint-Domingue, la más rica de las colonias francesas, para intervenir de manera subversiva, interesada y onerosa en el conflicto interno de dicha región. El fracaso de este intento imperial español, bien retratado en las despechadas declaraciones del ministro Godoy, ${ }^{71}$ conllevó incluso una pérdida mayor: la entrega total de La Española al poderío galo, su enemigo.

La ambición imperial española no se detuvo ante la ordinaria repulsa que provocaban estos negros revolucionarios de Saint-Domingue -considerados "casta infecta", 72 "hombres feroces" ${ }^{\text {"73 }}$, a los que tuvo que recurrir en sus aspiraciones, y que a fin de cuentas representaron una fuerte carga para su erario, a la vez que una aguda preocupación para su seguridad, dada su latente peligrosidad de estos nuevos vasallos de su majestad.

Tras la derrota de este proyecto de reconquista hispano de Santo Domingo sobrevino la necesidad de dispersar a sus antiguos aliados militares negros para prevenir una posible amenaza de su parte, ante la imposibilidad de cumplirles todas las ofertas hechas para obtener su lealtad. El problema fue estudiado en los más altos niveles diplomáticos, recayendo las decisiones en el propio presidente del Consejo de Ministros. Sin embargo, no hubo una so-

\footnotetext{
71 Véase la nota 28.

72 "El virrey marqués de Branciforte comunica ...", AGI, Estado, 24, N. 53.

${ }^{73}$ Porro, "Inquietudes", 1993, p. 167.
}

lución integral, y estas tropas auxiliares fueron dispersadas en varios puntos de las costas caribeñas y en la propia España, dejándose al paso del tiempo la conclusión del conflicto.

Yucatán fue uno de los dominios españoles ubicados en la tierra firme americana a donde se destinaron parte de las tropas auxiliares, y en este caso, un sector de las que estuvieron al mando de Jean François. El interés de esta distribución radicaba en los beneficios económicos que la presencia de este grupo podría representar para la provincia, merced a la difusión de las técnicas de cultivo y de desarrollo agrícola del sistema de plantación imperante en la colonia francesa, no obstante el reconocimiento del peligro que se corría por la posible difusión de sus "costumbres perniciosas". ${ }^{74}$ Fue así como a la península yucateca le tocó jugar un pequeño papel en el epílogo de la aventura imperial de la corona hispana en Santo Domingo.

\section{Bibliografía}

-Albi, Julio, La defensa de las Indias (17641799), Instituto de Cooperación Iberoamericana, Madrid, 1987.

-Bautista, Juan, La estrategia española en América durante el Siglo de las Luces, Editorial MAPFRE, Madrid, 1992 (Colecciones MAPFRE, 1992).

-Bojórquez Urzaiz, Carlos, "Haitianos rebeldes en Yucatán", Por Esto!, 20 de agosto de 1995, Mérida.

-Canto Alcocer, Jorge, "La revolución haitiana como mito caribeño. Extrapola-

74 "El virrey marqués de Branciforte comunica...", AGI, Estado, 24, N. 53. 
ciones infundadas en la historiografia regional: el caso de San Fernando Aké, Yucatán", VI Congreso Anual de la MERC, Campeche, abril de 1999.

_ Jorge Victoria Ojeda, "San Fernando Aké: conformación de un pueblo virreinal a fines del siglo Xvil", Cuadernos de Arquitectura, Facultad de ArquitecturaUniversidad Autónoma de Yucatán, núms. 11-12, 2000, pp. 163-167, Mérida.

-Díaz Polanco, Héctor, Autonomía regional. La autodeterminación de los pueblos indios, Siglo XXI, México, 1996.

-Franco, José Luciano, Rebeldias negras en los siglos $X V I I I$ y $X I X$, Universidad de La Habana, La Habana, 1975. Historia de la revolución de Haiti, Editora Nacional, Santo Domingo, 1971.

"El vudú como elemento de cohesión sociocultural entre los esclavos" en Grafenstein, Textos, 1988, t. I, pp. 128136.

-Gaspar, David y David Gegus, A turbulent time. The french revolution and the greater caribbean, Indiana University Press, Indianapolis, 1997.

-Grafenstein, Johanna von, Haiti, Instituto Mora/Universidad de Guadalajara/ Alianza Editorial Mexicana, México, 1988.

- Textos de la bistoria de Centroamérica y el Caribe. Haiti, Instituto Mora/Universidad de Guadalajara/Nueva Imagen, México, 1988.

Nueva España en el Circuncaribe, 1779-1808. Revolución, competencia imperial y vinculos intercontinentales, UNAM, México, 1997.

-Guerrero Cano, María, Santo Domingo (1795-1865), Servicio de Publicaciones de la Universidad de Cádiz, Cádiz, 1986.

-Joachim, Benoit, "Les racines du sousdéveloppement en Haití" en Johanna von
Grafenstein, Textos, 1988, t. I, pp.163-191.

-Landers, Jane G., "Rebellion and royalism in spanish Florida: the french revolution on Spain's northern colonial frontier" en Gaspar y Geggus, Turbulent, 1997, pp. 156-177.

-Landolfi, Ciriaco, "Una interpretación culturológica, desde las raíces de la primera república" en Mejía-Ricard, Sociedad, 1977, pp. 157-205.

-O'Neill, Misal diario. Propio de España y América, s.p.i.

-Mejía Ricard, Tirso, La sociedad dominicana durante la primera república. 1844-1861, Universidad Autónoma de Santo Domingo, Santo Domingo, 1977.

-Pichardo, B., Resumen de bistoria patria, Altes Impresor, Barcelona, España, 1922.

-Porro Gutiérrez, Jesús, "Inquictudes en la parte española de la isla, sobre la sublevación de los esclavos de Saint-Domingue", Revista de la Universidad de Alcala de Henares. Estudios de Historia Social y Económica de América, núm. 10, 1993, Madrid, pp. 165-179.

-Valdez, Antonio, Historia de la isla de Cuba y en especial de La Habana, Comisión Nacional Cubana de la UNESCO, La Habana, 1964.

-Victoria Ojeda, Jorge, Mérida de Yucatán de las Indias. Pirateria y estrategia defensiva, $\mathbf{H}$. Ayuntamiento/Grupo Corme, México, 1995.

y Jorge Canto Alcocer, "San Fernando Aké: microhistoria de una comunidad afroamericana en Yucatán (17961848)", inédito.

-Zapatero, Juan, La guerra en el Caribe durante el siglo XVIII, Servicio Histórico Militar/Museo del Ejército, Madrid, 1990. 


\section{SECUENCIA}

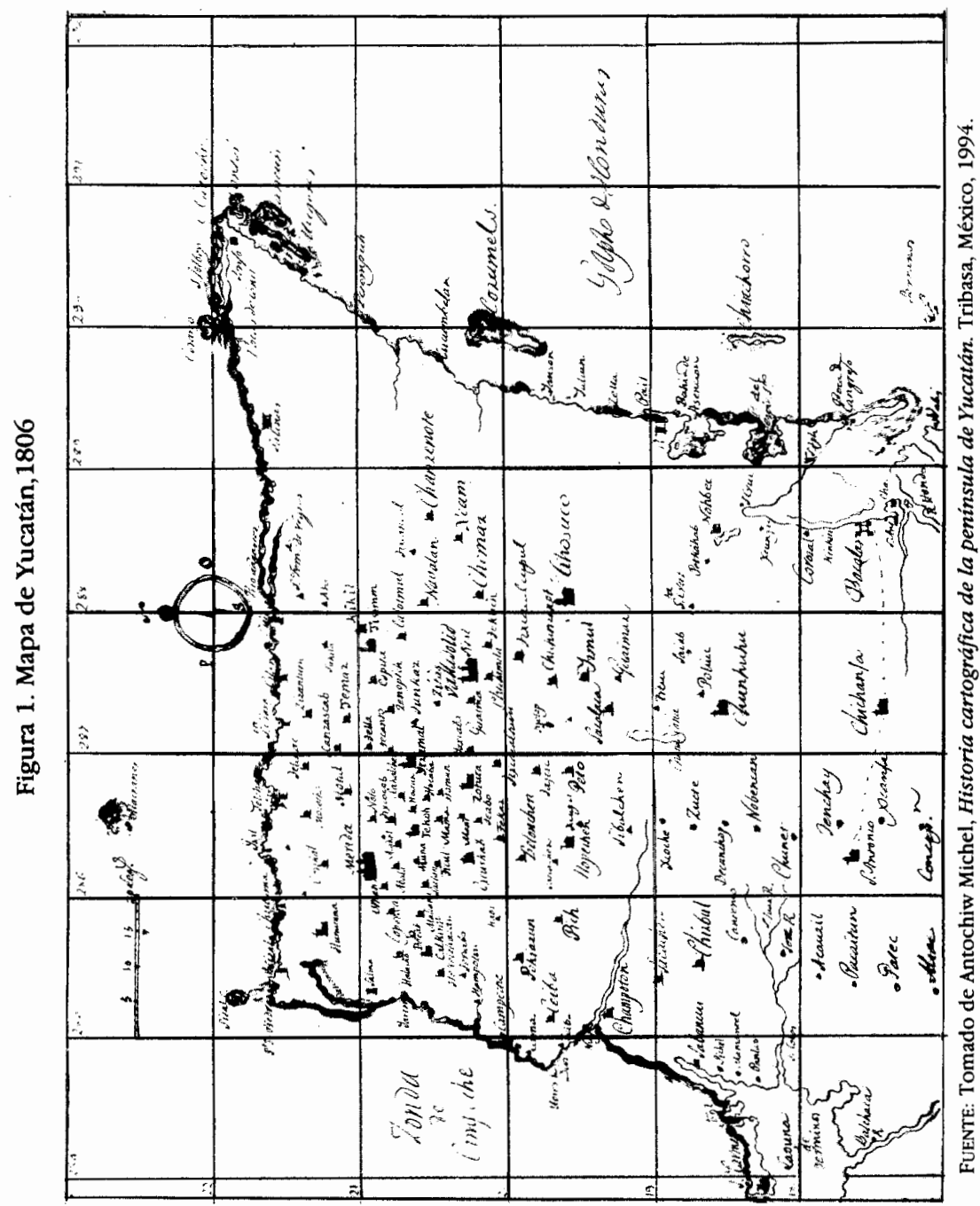




\section{SECUENCIG}

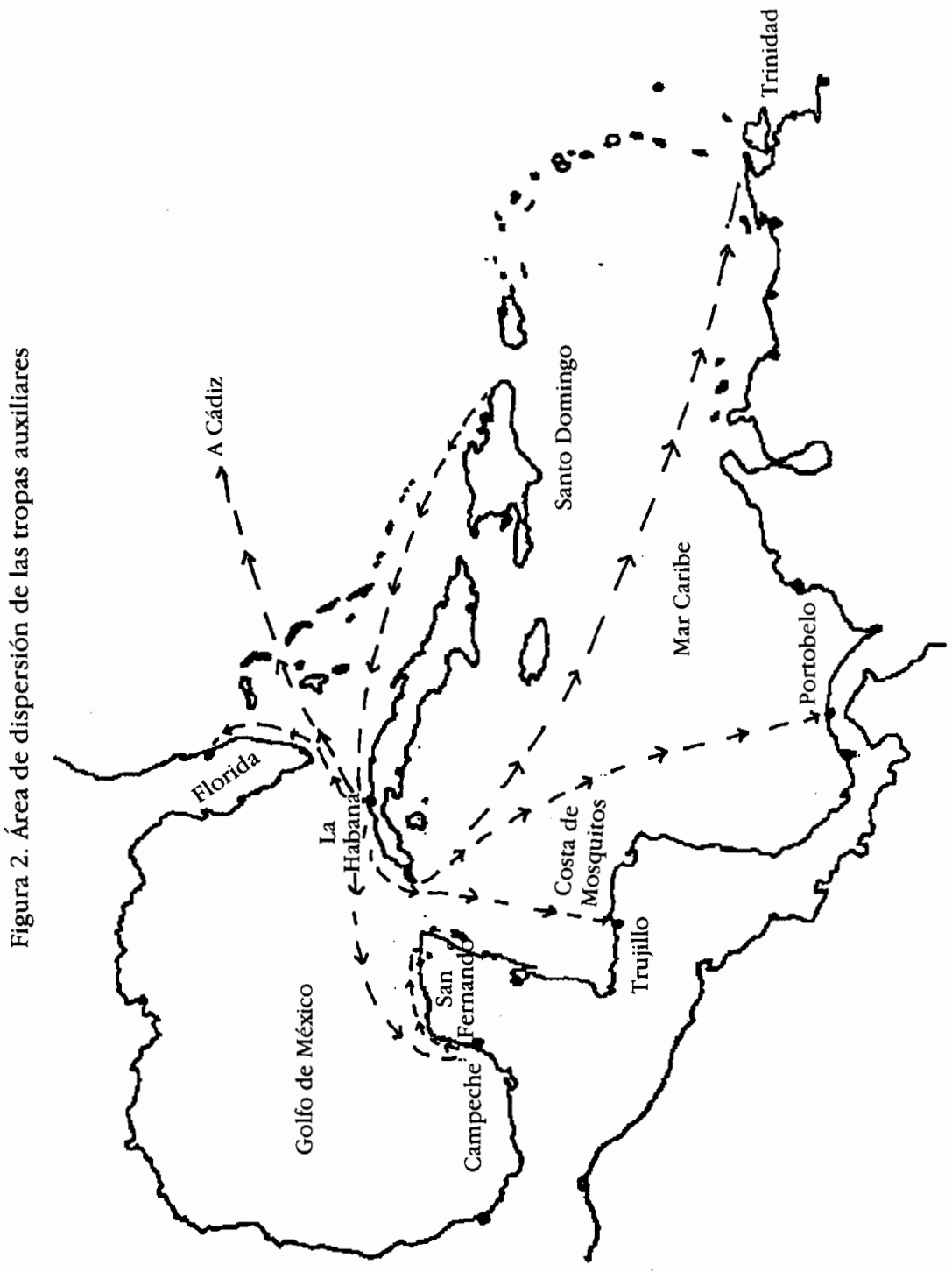

